\title{
A statistical approach to the evaluation of characters to estimate evolutionary relationships among the species of the aquatic subterranean genus, Iberobathynella (Grustacea, Syncarida)
}

\author{
ANA I. CAMACHO, ELISA BELLO \\ Museo Nacional de Ciencias Naturales, José Gutiérrez Abascal 2, 28006 Madrid, Spain
}

AND

GEORGE F. ESTABROOK

Department of Biology and University Herbarium, University of Michigan, Ann Arbor, $M I$ 48109-1048, U.S.A.

The 13 known species of the genus Iberobathynella were studied. Twenty-six characters with usually two or three states were revealed to have low within-species variability but show clear differences among some species. These characters were hypothesized to have states convex on the branching pattern of the phylogenetic lines that gave rise to these 13 species (i.e. be uniquely derived). Each pair of these hypotheses was tested for logical compatibility; then, for each character, a new character was created by choosing equiprobably one of the possible permutations of the 13 species to rename the species in each state. Characters created in this random way would have convex states only by chance, not by evolution. This random character was tested with each of the remaining 25 for logical compatibility as hypotheses of convexity. For each character, one thousand such random characters were created and tested. Sixteen observed characters were compatible with more other observed characters than $90 \%$ of their randomly generated counterparts, and so were considered plausibly non-random. They were used to speculate on branching patterns of the phylogenetic lines among the 13 species.

01997 The Linnean Society of London

ADDITIONAL KEY WORDS: - Grustacea - Iberobathynells - evolutionary relationships - evaluation of characters - simulations - compatibility - convex.

\section{CONTENTS}

Introduction

Taxonomy of Iberobathynella 
Characters of Iberobathynell

Statistical significance of characters .

Branching patterns . . . . . . . . . . . . . . . . . . . . . . . . 235

Discussion . . . . . . . . . . . . . . . . . . . . . . . . . . . 236

Acknowledgements . . . . . . . . . . . . . . . . . . . . . . . . . . . . . . . . . . . 240

References . . . . . . . . . . . . . . . . . . . . . . . . . 240

\section{INTRODUCTION}

The subterranean environment holds an immense attraction for the study of evolution because of its apparent simplicity and stability, and because of the general trend of its fauna toward the reduction or disappearance of some of the characteristics apparent in above ground relatives, such as loss of eyes and pigmentation. It is considered to be a promising place to look for new insights into adaptation and speciation (Rouch, 1986; Barr, 1968). Nevertheless, the pursuit of mechanisms that could explain the apparent independent acquisition or loss of similar features by unrelated taxa that live in similar environments (Romero, 1985) has produced long-standing controversies (Packard, 1885; Poulson \& White, 1969; Wilkens, 1971; Culver, 1982). Differing points of view often depend on which of several contradictory characters are considered most likely to have uniquely derived (convex) states in the context of the group under study. These then determine the presumed branching pattern of the phylogenetic lines, along which non-convex character states evolved in parallel (homoplastically). A method to evaluate characters in the light of these concepts, before they are used to estimate a branching pattern, would be useful in the resolution of such controversies. Here we apply an objective, statistical method (Meacham, 1981, 1994) to 26 characters of the 13 known species of Iberobathynella (Crustacea, Syncarida), a group of blind and unpigmented aquatic subterranean Crustacea. This method helps to decide which observed characters can be distinguished from characters generated at random (i.e. not in accordance with an evolutionary branching process). Estimates of branching pattern of the phyletic lines of the 13 species, based on 16 distinguished characters, are presented.

\section{TAXONOMY OF IBEROBATHYNELLA}

The order Bathynellacea (Crustacea, Malacostraca, Syncarida) to which the genus Iberobathynella belongs is exclusively aquatic and subterranean (interstitial milieu and caves) without any epigean representatives, with the possible exception of the species of Lake Baikal, which some consider to be epigean (Birstein \& Ljovuschkin, 1967). In 1882, Vejdvosky discovered the first living Syncarida, Bathynella natans, in a well in Praga. Since then, new findings have resulted from the continuous effort to explore the subterranean environment in new areas. Now 157 species of Bathynellacea are known worldwide, of which 71 belong to Bathynellidae (15 genera), and 86 belong to Parabathynellidae ( 28 genera). In the Iberian Peninsula, the first of the species under study was described as a Parabathynella by Braga in 1949. The genus, Iberobathynella, was erected as an isolate from Parabathynella in 1973 by Schminke, who made five new combinations at that time. Intensive sampling has increased this number to 11 species known from the Iberian Peninsula (Serban \& Comas, 1978; 
Camacho, 1987a, b, 1989a, b; Camacho \& Coineau, 1987), plus two species known from outside this area, I. maghrebensis in north Africa and I. califormica in north America. Another species, T. bowmani Delamare Debouttevile, Coineau \& Serban, 1975, was found in Texas (USA) and described as belonging to Texanobathynella, which was synonymized by Schminke (1986) as Iberobathynella. However, this publication does not refer to the original type specimens nor to specimens from the type locality; nor are such specimens available to us. Because we believe that synonymy should be based on the examination of the specimens in question, Texanobathynella bowmanni is kept here as such, and so excluded from our study. Table 1 presents the recognized names, dates, authors and synonyms of the 13 species of Iberobathynella considered in this study. The intensive collecting done by Camacho, Notenboom and Rouch has resulted in a large number of specimens from which morphology and variability can be studied. Specimens of $I$. califormica $(\mathrm{m})$ and $I$. maghrebensis (1) were not available for first hand study and so the description of these species were taken from the published literature. Because these species could not be directly observed, some possible additional bases for comparison may not have been revealed. This material is the basis of the work reported here. Except for I. californica (m) and I. maghrebensis (1), which were described from the literature, specimens of all species were examined at the Museo Nacional de Ciencias Naturales, Madrid (Spain) and additional specimens of $I$. asturiensis (b) and $I$. espaniensis (c) were also examined at the Institutul Speologie 'Emile Racovitza', Bucharest, Romania.

TABLE 1. Recognized species names and synonyms and authors of the genus Iberobathynella: Class Syncarida Packard, 1885

Order Bathynellacea Chappuis, 1915

Family Parabathynellidae Noodt, 1965

Genus Iberobathynella Schminke, 1973

Parabathynella Chappuis, 1926 partim.

(h) Iberobathynella lusilanica (Braga, 1949): Schminke, 1973 Parabathynella lusitanica Braga, 1949

Parabathynella lusitanica barcelensis Noodt \& Galhano, 1969

Parabathynella lusitanica valbonensis Galhano, 1970

(g) Iberobathynella fagei (Delamare Deboutteville \& Angelier, 1950): Schminke, 1973

Parabathynella fagei Delamare Deboutteville \& Angelier, 1950

(i) Iberobathynella gracilipes (Braga, 1960): Schminke, 1973 Parabathynella gracilipes Braga, 1960

(e) Iberobathynella mateusi (Galhano, 1967): Schminke, 1973 Parabathynella mateusi Galhano, 1967

(f) Iberobathynella cavadoensis (Noodt \& Galhano, 1969): Schminke, 1973 Parabathynella cavadoensis Noodt \&c Galhano, 1969

(c) Iberobathynella espaniensis Serban \& Comas i Navarro, 1978

(b) Iberobathynella asturiensis Serban \& Comas i Navarro, 1978

(l) Iberobathynella maghrebensis Boutin \& Coineau, 1987

(d) Iberobathynella imuniensis Camacho, 1987a

(j) Iberobathynella rouchi Camacho \& Coineau, 1987

(a) Iberobathynella ortizi Camacho, 1989b

(k) Ibembathynella notenboomi Camacho, 1989b

(m) Iberobathynella californica Schminke \& Noodt, 1988 


\section{CHARACTERS OF IBEROBATHYNELLA}

Members of the order Bathynellacea lack eyes and have an elongate, vermiform, almost cylindrical, unpigmented body. The body length is between $0.5 \mathrm{~mm}$ and $2 \mathrm{~mm}$ ( $3 \mathrm{~mm}$ in exceptional cases). The body is divided into cephalon, thorax and pleon (Fig. 1I). The cephalon has a thin cephalic capsule, two pairs of antennae (AI and AII), and mouthparts located ventrally.

In the genus Iberobathynella, the mouthparts comprise a labrum (Lb), mandible $(\mathrm{Md})$, first (MxI) and second (MxII) pairs of maxillae. The mouth opens in the
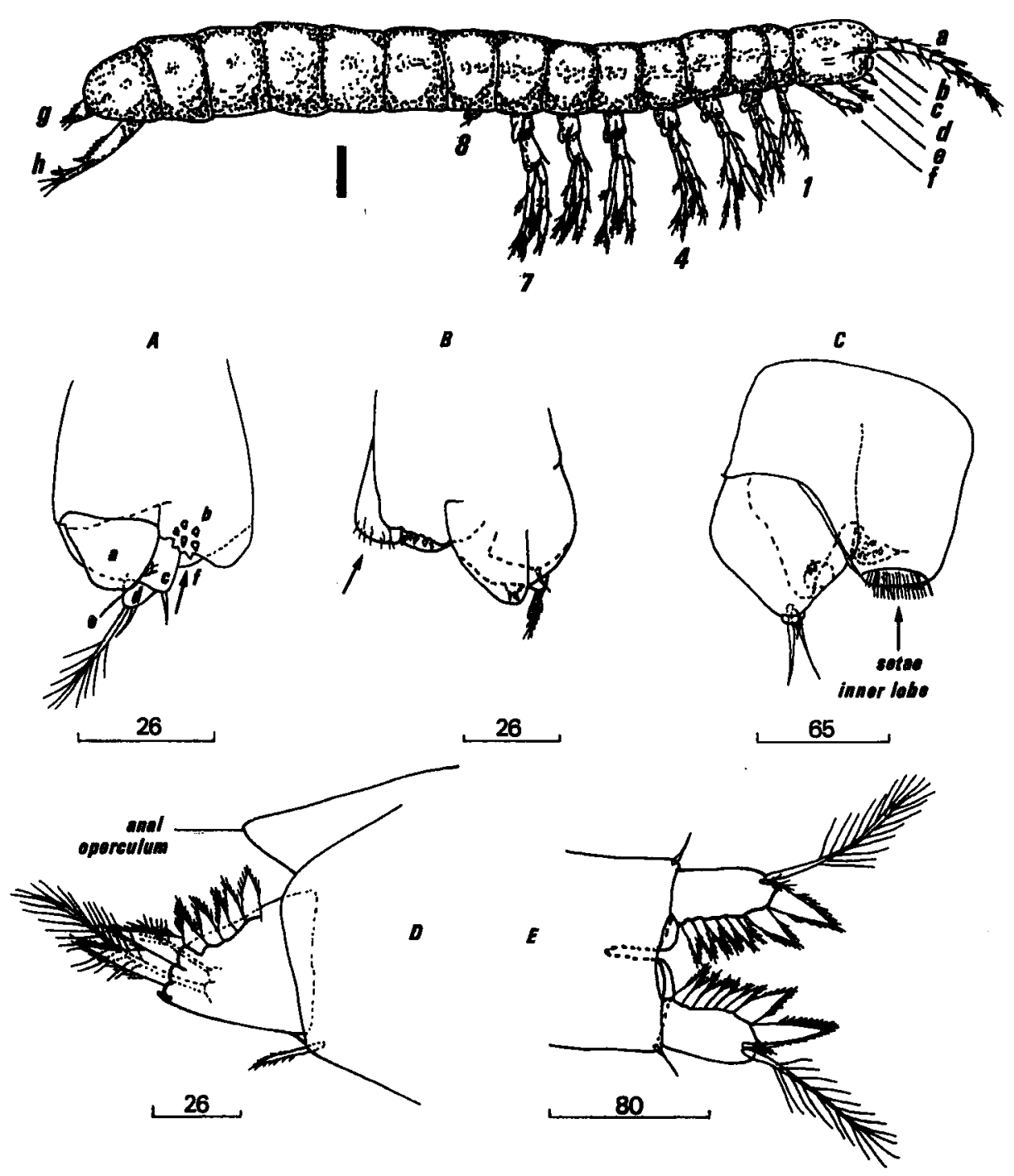

Figure 1. I Iberobathynella, habitus male. a - Antenna I; b - Antenna II; c - Labrum; d - Mandibles; e Maxilla I; f - Maxilla II; 1 to 7 - Thoracopods I through VII; 8 - Thoracopod VIII; $g$ - furca; $h$ uropod; A, thoracopod VIII male (I. ortizi). a - outer lobe; b - dentate lobe; c - basipod; d - endopod; e - exopod; f - inner lobe. B, thoracopod VIII male (I. asturiensis). C, thoracopod VIII male (I. gracilipes). $\mathrm{D}$, dorsal margin of pleotelson (lateral view) and furca (I. asturiensis). E, dorsal margin of pleotelson (dorsal view) (I. rouchi). Scale in $\mathrm{mm}$. 
posterior third rostral part. The first pair of antennae has seven segments, each with various kinds of smooth or plumose setae. Much of the variation among the species of Iberobathynella is here. Aesthetes are present in segments 5,6 and 7 with 3 aesthetes in segments 6 and 7 for all species but 2 or 1 in segment 5 (Fig. 2A,B). The second pair of antennae, similar in all species, has three segments: the first and second without setae but the third with three smooth setae (Fig. 2C). The labrum has 12 teeth (eight central plus a small pair at each end) and a superficial row of spines (Fig. 2D). The mandible consists of two parts: a distal part with a number of teeth of
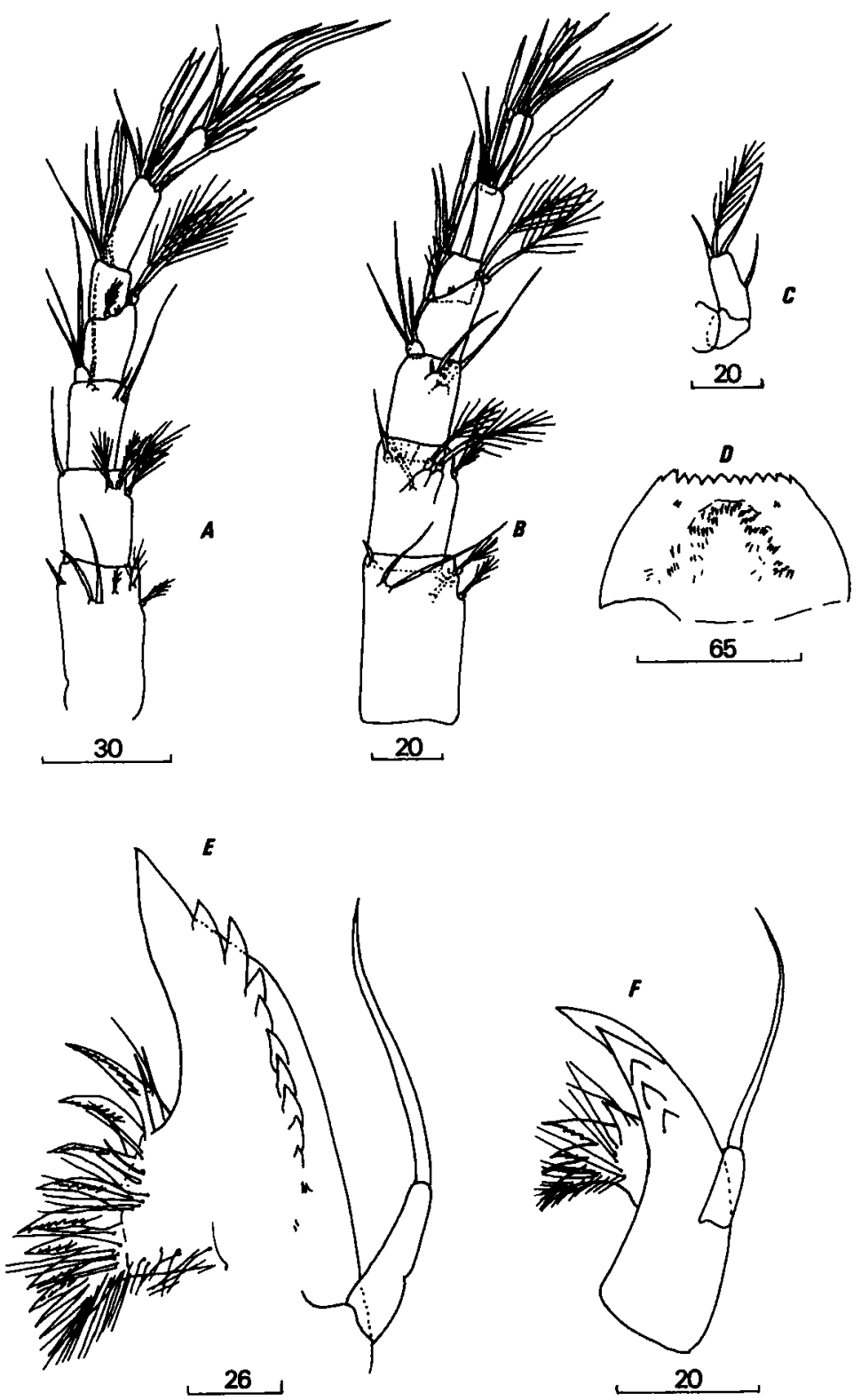

Figure 2. A, antenna I (I. ortizi); B, antenna I (I. asturiensis); C, antenna II (I. ortizi); D, labrum (I. imuniensis); $\mathrm{E}$, mandible (I. lusitanica); F, mandible (I. ortizi). Scale in $\mathrm{mm}$. 
variable size, and a proximal part bearing a profusion of setae and several teeth with denticles. Between these two parts is a tooth with one or two setae. The lengths of the mandibular palp and of its base are variable (Fig. 2E,F). The first maxilla has two endites: the proximal has 4 teeth with setae, and the distal has 4 or 5 teeth with denticles and 2 smooth teeth of different sizes (Fig. 3A,B). The second maxilla has three segments: the proximal with or without one smooth setae; the second with one smooth seta and 3 distal setae of different sizes; and the distal segment with from 14
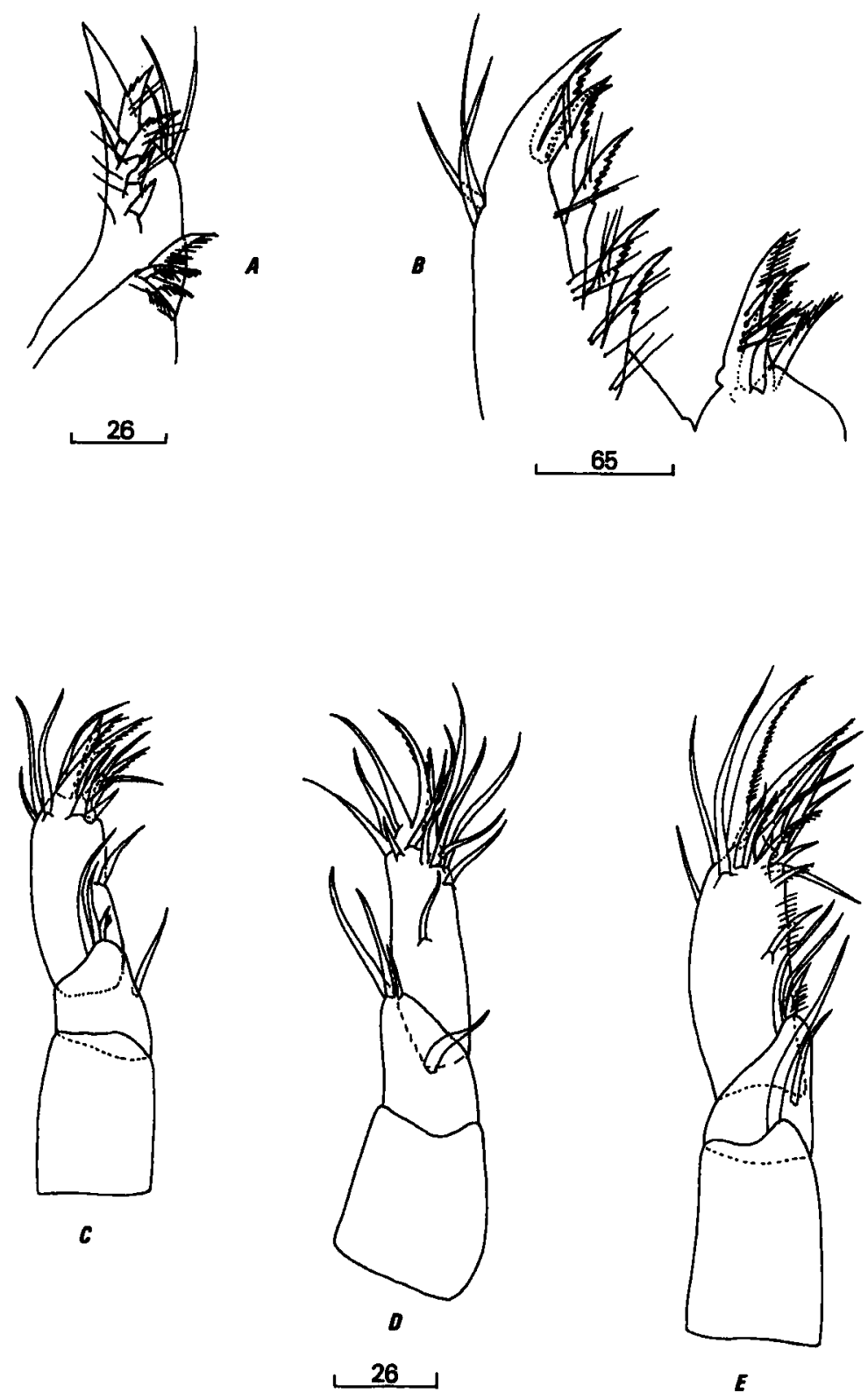

Figure 3. A, maxilla I (lateral view) (I. asturiensis); B, maxilla I (lateral view) (I. gracilipes); C, maxilla II (I. ortizi); D, maxilla II (I. mateusi); E, maxilla II (I. roucht). Scale in $\mathrm{mm}$. 
to 16 setae, some smooth and some toothed (Fig. 3C-E). The thorax has 8 clearly defined segments (I-VIII), each (usually) with a pair of bibranched thoracopods. On segments II through VII, there are epipodites for breathing. The pair of thoracopods on segment VIII is modified for sexual purposes in males and very reduced in females. Thoracopods I through VII have a distinct conical projection at the inner
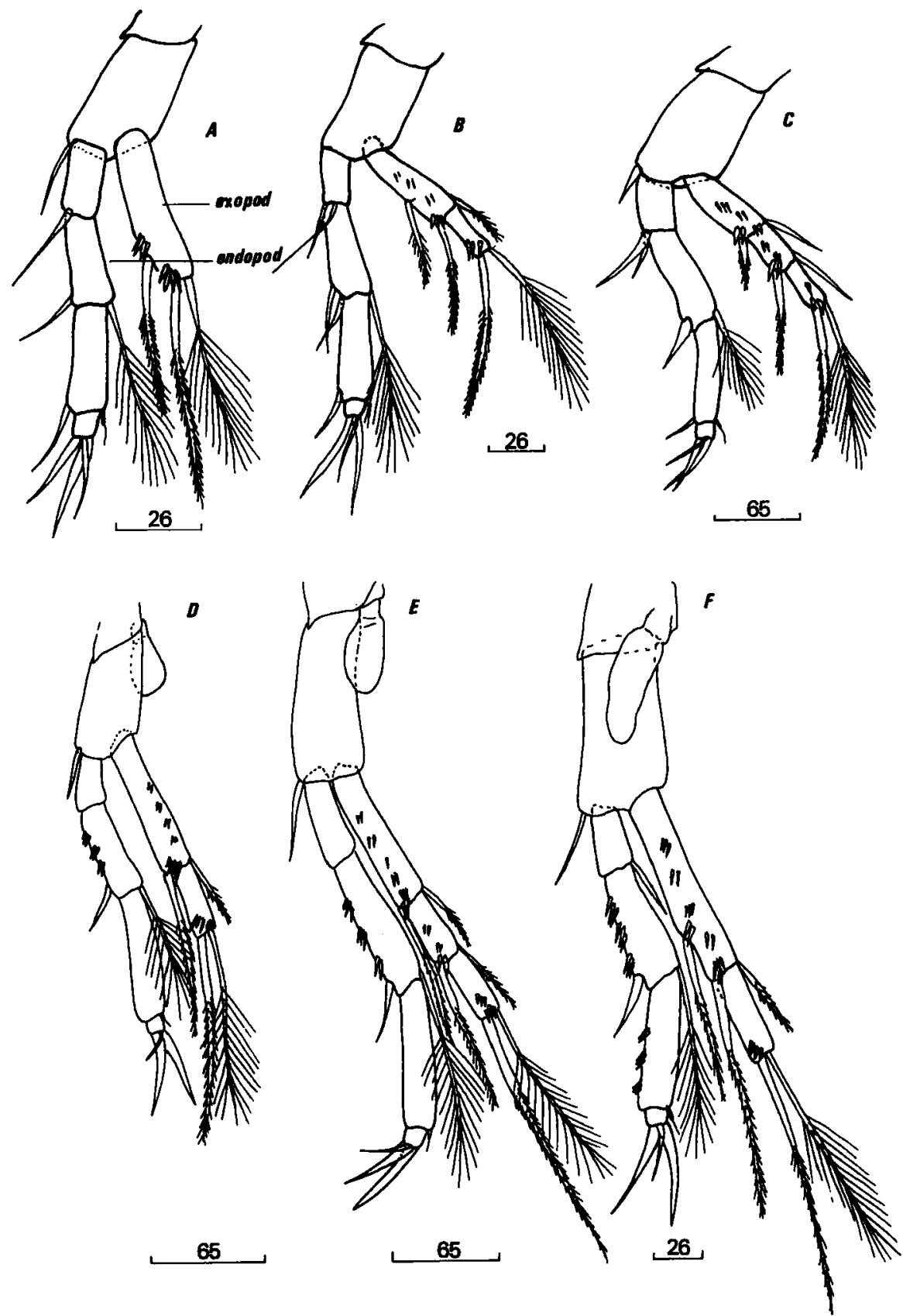

Figure 4. A, thoracopod I (I. ortizi); B, thoracopod I (I. lusitanica); C, thoracopod I (I. notenboomi); D, thoracopod III (I. imuniensis); E, thoracopod III (I. fage ); F, thoracopod III (I. lusitanica). Scale in mm. 
distal border of the coxa and a seta at the distal end of the basipodite. Thoracopod I has an exopod of 1, 2 or 3 segments with 2 or 3 setae in the first, 2 terminal setae in the second, and 1 barbed and 1 plumose seta in the third. Thoracopod I has an endopod of 4 segments with 1 or 2 smooth setae on the basal segment, 1 plumose and 1 or 2 smooth setae on the second segment, smooth seta and 1 small seta with a long cilia on the third segment, and two claws of the same size plus one smooth seta on the distal segment (Fig. 4A-C). Thoracopods II to VII have an exopod of 2, 3 or 4 segments with 2 or 3 setae on each segment, all barbed except for 1 plumose seta on the distal segment. The endopods are similar in all the species, with the following setal formulas: $0-2-1-3$ or 1-2-1-3; the proportion of each among species is variable (Fig. 4D-F). The segments of male thoracopod VIII (Fig. 1A-C) are modified; they have a dentate lobe with 6 to 8 teeth (Fig. 1Ab), and an inner lobe with setation varying from absent to dense (Fig. 1Af). The segments of female thoracopod VIII (Fig. 5A-C) are variable in size, shape, and position of the tooth, but the cuticule is usually smooth (Fig. 5A and C) or wrinkled (Fig. 5B). The pleon has 5 free segments without pleopods, and a pleotelson. The pleotelson is broader on the dorsal side, with a seta at each side; it is narrower on the ventral side where the uropods articulate. The uropod has a sympod with a comb of a variable number of barbed spines (also variable within a species as a function of size) (Fig. 5G-I). The relative sizes of sympod, exopod, and endopod vary with species (Fig. 5D-F). The exopod has 3 or 4 terminal or subterminal barbed setae and a barbed, smooth or plumose basal seta. The endopod has 2 or 3 barbed, smooth, or plumose setae of different sizes. The dorsal side of the pleotelson ends in furcal lobes, and the dorsal edge ends in a more or less pronounced anal operculum (Fig. 1D,E). The furca has from 6 to 12 barbed spines, variable even within species, of which the two distal spines are larger and bear one short (smooth, barbed or plumose) and one long plumose dorsal seta (Fig. ID,E).

Camacho (1987b) reported an exhaustive morphological study of all the species of Iberobathynella. Bases for comparison with which two or more groups of species could be distinguished and for which within species variability was small compared to differences among these groups, were structured into the 26 qualitative taxonomic characters presented in Table 2.

\section{CONVEXITY OF CHARACTER STATES}

In order to use these characters to estimate the tree branching pattern of the phylogenetic lines along which the species of Iberobathynella evolved, there must be a relationship between those phylogenetic lines and these characters. If the species comprising a state of a character share the common property of that state because that property did not change during the evolution of these species from their most recent common ancestor, then all the phyletic line segments of species with that property form a contiguous piece of that tree of phylogenetic lines. Such a contiguous piece of a phylogenetic tree is said to be convex because any two species in that piece are connected by a unique path of phylogenetic line segments along which all species also have that property. A qualitative taxonomic character is thus an hypothesis about convex pieces of the phyletic lines. It hypothesizes that the character states are convex on the historically correct phylogenetic tree.

The species in a non-convex state would share their common property, not 
because it evolved without change during the evolution of these species from their most recent common ancestor, but because of some other reason. A mistake in homology would result in the comparison of two species based on parts that had not
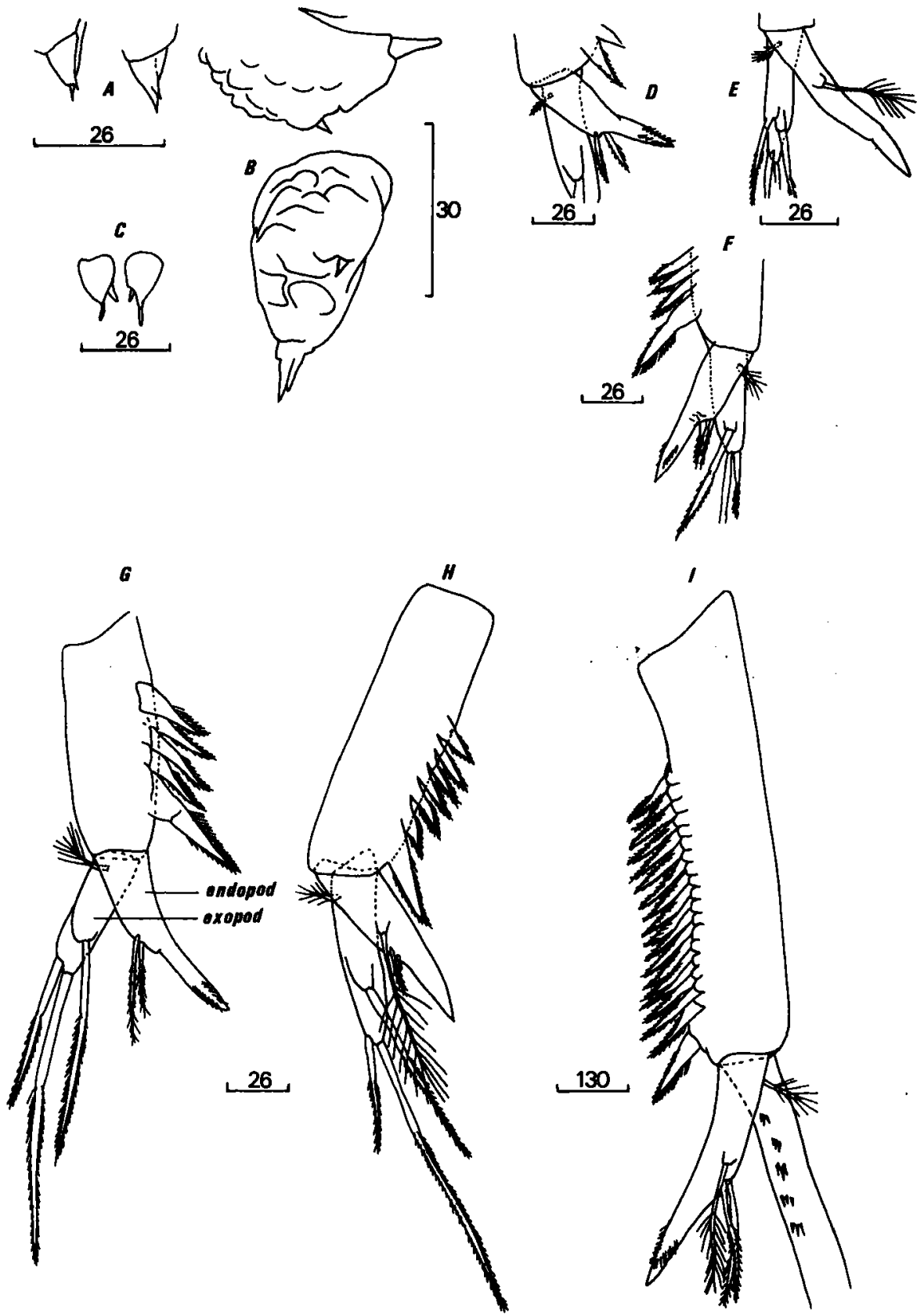

Figure 5. A, thoracopod VIII female (I. cavadoensis); B, thoracopod VIII female (I. asturiensis); C, thoracopod VIII female (I. ortizi); D, uropod: endopod (I. asturiensis); E, uropod: exopod and endopod (I. fage $)$; F, uropod: exopod and endopod (I. cavadoensis); G, uropod (I. ortizi); H, uropod (I. rouchi); I, uropod (I. gracilipes). Scale in $\mathrm{mm}$. 
TABLE 2. Qualitative taxonomic characters (numbered) for Iberobathynella, together with summaries of the common property unifying each state (capital lettered) of species followed by the letter names of the species in that state: $\mathrm{a}=I$. ortizi; $\mathrm{b}=I$. asturiensis; $\mathrm{c}=I$. espaniensis; $\mathrm{d}=I$. imuniensis; $\mathrm{e}=I$. mateusi; $\mathrm{f}=I$. cavadoensis; $\mathrm{g}=I$. fagei $\mathrm{h}=I$. lusitanica $; \mathrm{i}=I$. gracilipes; $\mathrm{j}=I$. rouch $;$ $\mathrm{k}=I$. notenboomi $\mathrm{l}=I$. maghrewbensis; $\mathrm{m}=I$. californica

1. Number of smooth setae on 1st segment of Antenna I
A: 2 setae
B: 3 setae
a, b, c
d, e, g, h, i, j, $\quad \begin{array}{lll}\text { k, } & \text { m }\end{array}$

2. Number of plumose setae on 1st segment of Antenna I

A: 2 setae

B: 3 setae

C: 4 setae

3. Number of smooth setae on 2nd segment of Antenna I
A: 1 seta
B: 2 setae
a, b, c, d, e, f, g, i, j, k
C: 3 setae

4. Number of smooth setae on 3rd segment of Antenna I

A: 2 setae

B: 3 setae

C: 4 setae

5. Thoracopod VII

A: absent

B: present

$\begin{array}{lllllll}\text { a, b, } & \text { g, } & \text { h, } & \text { i, } & \text { k, } & \text { l, } & \text { j } \\ \text { d, } & \text { e, } & \text { f }\end{array}$

Number of smooth setae on 5 th segment of Antenna 1

A: 3 setae

B: 4 setae

7. Number of aesthetes on fifth segment of Antenna I

A: 1 aesthete

B: 2 aesthetes

8. No. teeth with denticles on distal part of Maxilla I

A: 4 teeth

B: 5 teeth

9. Setae of 1st segment of Maxilla II

A: absence

B: presence

10. Number of setae on 3rd segment of Maxilla II

A: 14 setae

B: 15 setae

C: 16 setae

11. Cutcile of thoracopod 8 female A: smooth

B: wrinkled

12. Size spines on sympod of uropods

A: similar

B: different

13. Number of spines on sympod of uropods

A: 5 setae

B: 6-15 setae

C: more than 16 setae

a, c, d, f, g, h, i, j, k, l, $\quad$ m

14. Ctenidia on exopod of uropods

A: absence

B: presence

15. Number of distal setae on exopod of uropods

A: 3 setae

B: 4 setae

16. Type of basiventral setae on exopod of uropods

A: smooth

B: barbed

C: plumose

17. Number and type of setae on endopod of uropods

A: 2 barbed similar setae

B: 2 barbed different setae

C: 1 barbed, 1 plumose and 1 smooth

D: 1 plumose setae

E: 2 barbed and 1 plumose setae

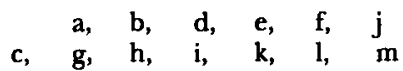

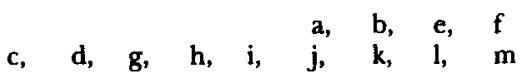

a, c, d, e, f, g, h, i, j, k, l, m

a $, \quad f, \quad g, i, k$

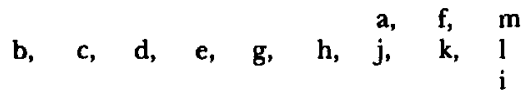

a, b, c, d, e, f, g, j, k, l, m

h, i

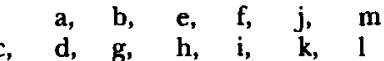

d, $\quad k, \quad l, \quad m$

b, e, f

c, d, g, $\begin{array}{ll}\text { k, } & \text { m } \\ \text { h, } & \mathbf{i}\end{array}$ 
evolved from the same part in the most recent common ancestor of those two species. Character states erected on such mistaken comparisons would not necessarily be convex pieces of the tree of branching phylogenetic lines of the species of Iberobathynella. If two species in a character state had come to possess the feature common to all species in that character state as a result of two separate evolutionary change events that evolved the feature from an ancestor that lacked it, then that character state would not be convex; the sequence of phylogenetic line segments connecting these two species would have to pass through an ancestor that lacked the feature and thus would not belong to the character state. This could happen either by parallel evolution or by the loss of a formerly evolved feature. The use of a nonconvex character state as evidence of phylogenetic contiguity could lead to errors in estimating the branching pattern of phylogenetic lines.

Ideally, we would like to be able to identify non-convex character states and avoid them. This can almost never be done with absolute certainty. However, for any pair of characters, a simple test can be performed to determine whether it is logically possible for all the states of both characters to be simultaneously convex on any phylogenetic tree (Estabrook \& Landrum, 1975; Estabrook \& McMorris, 1977; Estabrook, 1983). If this is possible, then the two characters are said to be compatible as hypotheses of convexity. In particular, if it is not logically possible for all states of two characters of the species of Iberobathynella to be simultaneously convex on any

TABLE 2. (continued)

18. Anal operculum of pleotelson

A: not pronounced

B: pronounced

19. Number of segments of exopod of thoracopod I

A: 1 segment

B: 2 segments

C: 3 segments

20. Type and No. setae on exopod of thoracopod I

A: 1 barbed and 1 plumose on 1 segment

B: 2 barbed and 1 plumose on 1 segment

C: 3 barbed and 1 plumose on two segments

D: 4 barbed and 1 plumose on two segments

E: 3 barbed, 2 smooth and 1 plumose on 3 segments

21. No. smooth setae on segment 1 of endopod of thoracopod I

A: 1 seta

B: 2 setae

22. No. smooth setae on segment 2 of endopod of thoracopod 1

A: 1 seta

B: 2 setae

c, d, g, h, i, j, k, l

a, b, e, f, $\quad \mathrm{m}$

a, b, e, f, j, m

c, d, h, i, l

g. $\mathbf{k}$

23. Number of segments of exopod of thoracopod II to VI
A: 2 segments
B: 3 segments
a, b, c, d, e, f, h, i, j, m
C: variable

$\begin{array}{llll}\text { a, b, } & \text { e, } & \text { f, } & \text { j } \\ & \text { c, } & \text { d, } & \text { 1 } \\ & \text { h, } & \text { i } \\ & & \text { g, } & \text { k }\end{array}$

24. No. setae on segment 1 of exopod of thoracopod II to VI
A: 2 setae
a, b, c,
B: 3 setae
25. Setae on segment 1 of endopod of thoracopod II to VI
d, e, f, g, j, k, l, m
A: absent
a, b, c, d, e, f, g, j, k, l, m
B: present
26. Type of inner lobe of male thoracopod VIII
A: without setae
B: with dense setae
C: with sparse setae
a, d, e, f, $\quad$ g, j, $\quad$ k, $\quad$ l, $\quad$ m
h, i
b, c 
tree, then at least one state of at least one character must be made of two or more distinct convex pieces of the historically correct phylogenetic tree for Iberobathynella. Such non-convex character states would have to be explained by postulating losses, parallel evolution, mistakes in homology, etc., as discussed above. Notice that two characters whose states are convex on the historically correct phylogenetic tree for Iberobathynella are, a fortiori, compatible.

To test the compatibility of a pair of characters as hypotheses of convexity, one may first make a contingency table. This is a rectangular array with the states of one character labelling the rows and the states of the other character labelling the columns. At each intersection of row and column are placed the names of the species that belong to the state of both row and column. Some intersections may be empty. One then begins at any non-empty intersection and moves to any other non-empty intersection in the same row or column; one then moves, if possible, to another nonempty intersection in the same row or column as the present one, but without retracing the previous path. If it is possible to continue to move in this way until one returns to the intersection where one started, then the two characters are not compatible as hypotheses of convexity. If, irrespective of the starting position, it is impossible to return to it, then the two characters are compatible as hypotheses of convexity. To illustrate this technique, we present three examples of pairs of characters from Table 2.

Figure 6a shows the test for characters 12 and 23. The species have been placed in the contingency table according to the states to which they belong. For example, species h (I. lusitanica, Table 1) belongs to state B of Character 12 and to state A of Character 23, species $\mathrm{g}($ I. fagel) belongs to state $\mathrm{A}$ of Character 12 and to state $\mathrm{C}$ of Character 23, and so forth. It is possible that a path on the phylogenetic tree from some species in state $23 \mathrm{~A}$ to some species in state $23 \mathrm{~B}$ could pass through species only in state $12 \mathrm{~B}$. A path from a species in $23 \mathrm{~A}$ to a species in $23 \mathrm{C}$ could pass through species only in 12A. Therefore, in character 23 state A could be between B and C, and could contain species in both state 12A and 12B, to allow these states to be convex on any of several tree branching patterns that contain these species at nodes and tips.

Figure $6 \mathrm{~b}$ shows the test for characters 23 and 16 . Here we can pass from state $23 \mathrm{~A}$ to state $23 \mathrm{C}$ within state $16 \mathrm{~A}$ and also within state $16 \mathrm{C}$. So if the states of 23 are convex then the states of 16 cannot be convex. Consequently, there is no tree on which the states of characters 23 and 16 can all be simultaneously convex. These characters are not compatible as hypotheses of convexity.

Figure 6C tests Characters 19 and 23. Here the species in 23C occur only in 19G. To indicate how these two character states might be next to another in their respective characters on a tree where all states are convex, we must hypothesize the existence of an unobserved species in one of the empty boxes. It cannot be in box (23B, 19A) because that would make these characters no longer compatible and would also fail to show proximities with the isolated states. It could be in (23C, 19B), which would require $B$ between $A$ and $C$ for 19 , but not constrain proximities for 23 . It could be in (23C, 19A), which would require A between $\mathrm{C}$ and $\mathrm{B}$ for both characters. There are other possibilities that show branching patterns on which all states of both characters are convex. 


\section{STATISTICAL SIGNIFICANCE OF CHARACTERS}

This algorithm was applied to all pairs of characters in Table 2 to test their compatibility as hypotheses of convexity using the computer program POTENT (Estabrook, 1993). For each character in Table 2, the number of other characters (among the remaining 25) with which it is compatible is given in Table 3. Are any of these characters exceptionally consistent, as hypotheses of convexity, with the rest? Is there a group that is exceptionally internally consistent? Are there some characters with levels of consistency with others that are no greater than would be expected if the properties on which they were based were assigned at random, instead of inherited without change from common ancestors? With answers to these questions,

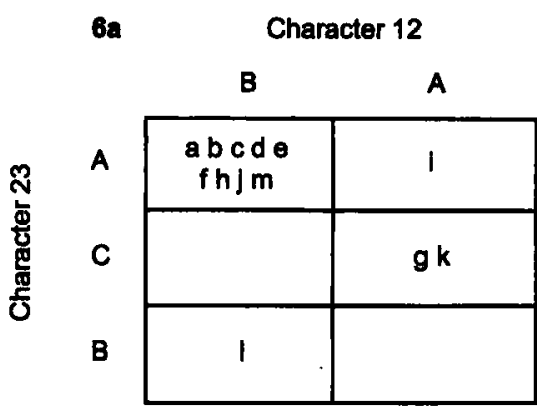

6b Character 16

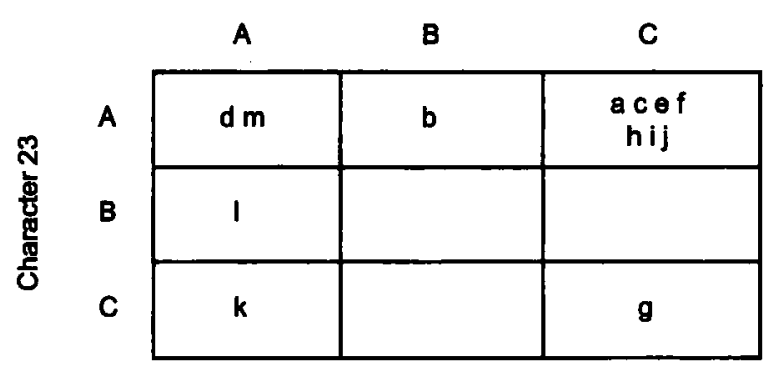

6c

Character 19

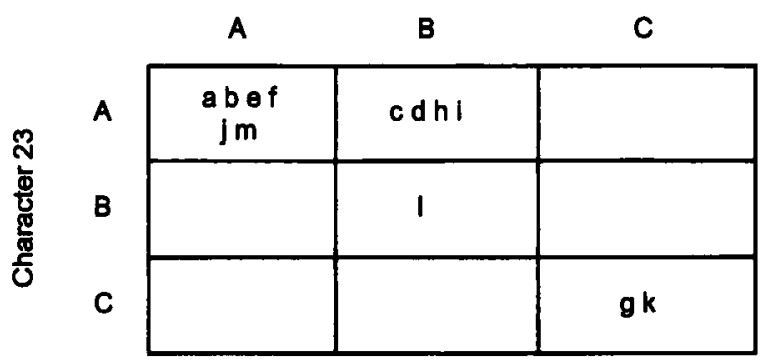

Figure 6. Potential compatibility of a pair of characters. (a) Characters 23 and 12 are compatible; (b) Characters 23 and 16 are not compatible; (c) Characters 23 and 19 are compatible. 
we can begin to choose those characters that may reflect more accurately the branching pattern of the phylogenetic lines of Iberobathynella, and to avoid those that may be misleading.

We use simulation to calculate the probability distribution for the number of other characters with which a given one would be compatible at random. We use a concept of random suggested by Meacham (1981) in which a given character is replaced with one chosen equiprobably from those obtained from it by permuting the names of the species. In this way the numbers of species in each state of the simulated character remains the same as in the given character, but the properties of the given character's states are assigned at random to the species of Iberobathynella. Now, this random character is tested for compatibility with each of the 25 other characters in Table 2, and the number of other characters with which it is compatible is counted. A new random character is simulated and tested in this way one thousand times to produce one thousand counts. These are added together and divided by one thousand to estimate very accurately the expected number of other characters with which the given one would be compatible at random.

This simulation was done using the computer program GPSEQ(Meacham, 1994). For each character in Table 2, the resulting number of other characters with which it would be expected to be compatible at random, and the fraction of simulated characters with as many or more than the observed number of compatibilities with the other characters, are also presented in Table 3.

Characters that are no more compatible with the other characters than would be expected of their random counterparts are not very credible as evidence of convexity.

Table 3. The number of the remaining 26 characters with which each character is observed to be compatible, the expected number, the fraction of simulated characters compatible with as many or more, and significance: $+=<0.2, *<0.1, * *<0.05, * * *<0.01$

\begin{tabular}{cccc}
\hline Character & Observed & Expected & Fraction \\
\hline 1 & 9 & 14.404 & 0.952 \\
2 & 9 & 7.078 & 0.279 \\
3 & 16 & 14.661 & 0.451 \\
4 & 8 & 11.066 & 0.833 \\
5 & 25 & 25.000 & 1.000 \\
$6+$ & 10 & 6.490 & 0.115 \\
$7^{*}$ & 21 & 14.708 & 0.085 \\
$8^{* *}$ & 19 & 6.385 & 0.018 \\
$9^{* * *}$ & 19 & 8.281 & 0.003 \\
10 & 6 & 4.940 & 0.350 \\
11 & 25 & 25.000 & 1.000 \\
$12^{*}$ & 16 & 10.371 & 0.080 \\
$13^{*}$ & 17 & 10.886 & 0.083 \\
$14^{* *}$ & 22 & 14.476 & 0.041 \\
$15^{* * *}$ & 17 & 6.451 & 0.002 \\
16 & 9 & 8.670 & 0.482 \\
$17^{* *}$ & 14 & 6.151 & 0.014 \\
$18^{* * *}$ & 18 & 6.841 & 0.002 \\
$19^{* * *}$ & 16 & 5.425 & 0.002 \\
$20^{* * * *}$ & 16 & 6.037 & 0.003 \\
$21^{* * *}$ & 19 & 8.187 & 0.002 \\
$22 * *$ & 14 & 6.966 & 0.016 \\
$23^{* *}$ & 22 & 14.647 & 0.053 \\
$24^{*}$ & 22 & 14.602 & 0.058 \\
$25^{* *}$ & 22 & 14.558 & 0.040 \\
26 & 9 & 9.364 & 0.565 \\
\hline
\end{tabular}


They look the same as random characters. Examination of Table 3 suggests that characters $1,2,3,4,5,6,10,11,16$ and 26 are about as consistent with the other characters as we would expect at random. Since characters 5 and 11 do not exclude any possible convex groups, they are necessarily compatible with any and every character. Characters 7, 12, 13, 23 and 24 are compatible with somewhat more other characters than would be expected at random, while 8, 14, 17, 22 and 25 are more clearly non-random. Characters 9, 15, 18, 19,20 and 21 have levels of compatibility that would be virtually impossible for random characters.

\section{BRANCHING PATTERNS}

Among these 16 plausibly non-random characters, three large groups are mutually compatible. The largest, with 12 characters $(7,9,14,15,17,18,19,20,21,23,24$ and 25), determines the branching pattern of phyletic lines shown in Figure 7, on which all of their character states are simultaneously convex. Characters 5 and 11 distinguish only one species from the rest. They may describe interesting properties but they assert nothing about convexity so they are consistent with any diagram of evolutionary proximities. They are included in Figure 7.

It is interesting to note that characters 8 and 22 are very significantly non-random, but one or the other is not compatible with characters 15,17, 18,19,20 and 23, and so cannot be included with convex states in Figure 7. However, 22 is compatible with $7,9,14,15,17,18,21,24$ and 25. These 10 characters, together with 5 and 11 , determine the branching pattern of phyletic lines shown in Figure 8, on which all of their character states are simultaneously convex. Characters 8 and 22 are compatible with each other and with 7, 9, 14,21, 24 and 25. These eight characters, together with 5 and 11, determine the branching pattern of phyletic lines shown in Figure 9, on which all their character states are simultaneously convex.

Characters 8 and 22 are compatible with each other and with 7, 9, 14, 21, 24 and 25. These eight characters, together with 5 and 11 , determine the branching pattern of phyletic lines shown in Figure 9, on which all their character states are simultaneously convex.

All 16 significant characters plus the almost significant character 6 were considered simultaneously by PAUP (Swofford, 1993) using branch and bound to reveal all most parsimonious undirected trees, of which there were 12 . All 12 are refinements of the tree shown in Figure 7. No refinements of the trees shown in Figures 8 or 9 were among the most parsimious trees. It is instructive to note that if one asks PAUP to conduct a heuristic search and not to collapse phylogenetic line segments of zero length, then 45 most parsimonious trees are created by making meaningless resolutions of these 12 trees by adding phylogenetic line segments that are not supported even by hypothesized homoplasies. If one went on to make a consensus of these 45 trees, then one would be compounding the meaninglessness of these unsupported resolutions.

The 12 trees arise as three partial resolutions of the node (f) times four partial resolutions of the node (c,d) in Figure 7, as shown in Figure 10. The X's arise from connecting ( $f$ ) anywhere along the phylogenetic line segment from (a) to the ancestor of $(b, e)$, which is succinctly and clearly shown in Figure 7 by leaving $(f)$ at the node. The Y's arise by clearly placing (d) towards the X part of the tree, as in Figures 8 and 9 , and showing four variations on the placement of (c) and (l) on an otherwise 
resolved area of the tree. In all cases, (c) and (l) are attached at or next to the node connecting the ancestor of $(\mathrm{h}, \mathrm{i})$ with the ancestor of $(\mathrm{g}, \mathrm{k})$.

\section{DISCUSSION}

Our approach to the study of evolutionary relationships among the 13 known species of Iberobathynella has been first to choose characters on the basis of low variability within species and clear, stable distinctions among species. Then we evaluate characters for compatibility as hypotheses of convexity (unique evolutionary change events). Next we simulate random characters to determine for each observed character the frequency with which random characters like it would have as many or more compatibilities with the other characters than actually observed. Sixteen of 24 contradictable characters were plausibly non-random. Of these, 12 were consistent with one branching pattern of phyletic lines, and 10 were consistent with another, and 8 were consistent with a third.

Parsimony analysis, which resolves polyclotomies by hypothesizing homoplastic

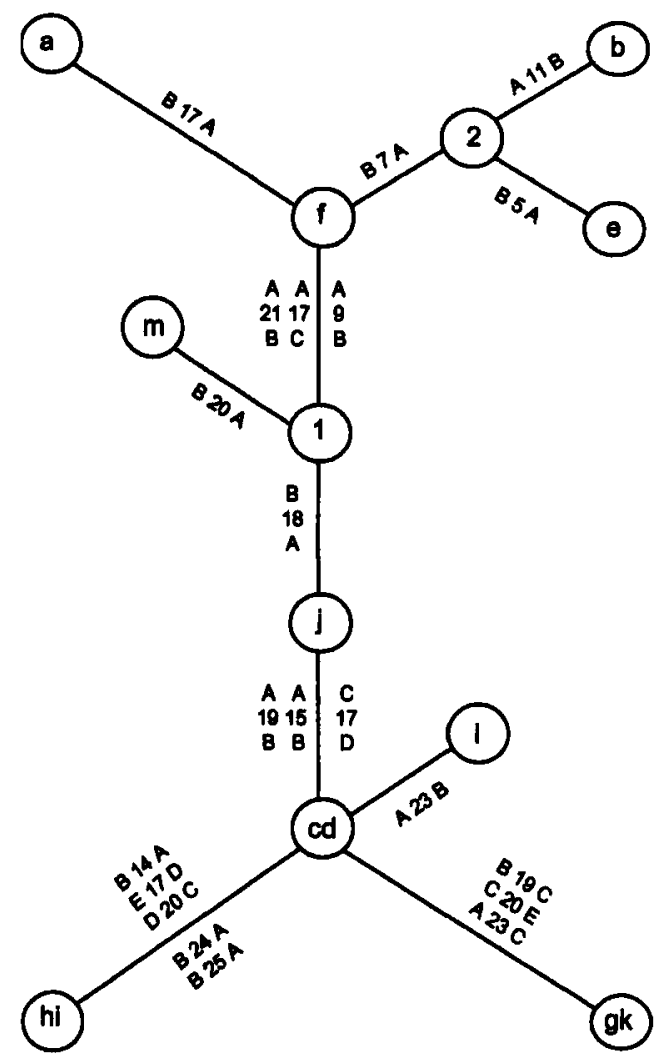

Figure 7. Undirected branching pattern for characters $5,7,9,11,14,15,17,18,19,20,21,23,24$ and 25 of Table 2 and the 13 species of Iberobathmella. $\mathrm{a}-I$. ontizi; $\mathrm{b}-I$. asturiensis; $\mathrm{c}-I$. espaniensis; $\mathrm{d}-I$. imuniensis; $\mathrm{e}-I$. mateusi; $\mathrm{f}-I$. cavadoensis; $\mathrm{g}-I$. fage $; \mathrm{h}-I$. lusitanica; $\mathrm{i}-I$. gracilipes; $\mathrm{j}-I$. rouchi; $\mathrm{k}-I$. notenboomi; I - I. maghrebensis, $\mathrm{m}-I$. californica. Lines are labelled with the evolutionary events that are hypothesized to have taken place to create the states observed. These are referred to with the character numbers in Table 2. Letters of character states are toward the species that they contain. 
evolutionary changes, revealed that only resolutions of the tree determined by the largest group of characters (excluding 8 and 22) comprised the 12 most parsimonious trees. These show how hypotheses of homoplasy in character 13 generate resolutions of the polyclotomy of $(f)$, and in characters 6,12 , and 22 generate resolutions of the polychotomy at $(\mathrm{c}, \mathrm{d})$. The participation of characters 6 and 8 in the parsimony analysis helps resolve the placement of (d). Here, where only a little homoplasy need be hypothesized by parsimony, the use of differentially resolved subtrees shows these resolutions more clearly than would a consensus tree.

These diagrams are estimates, and as such may not be historically correct. However our approach has been at every turn to evaluate the bases for comparison (characters) by objective, statistical means so as to consider those that might most accurately indicate convex groups and hence unique evolutionary changes. Three plausible branching patterns emerge. One (Fig. 7) contained among its resolutions all the most parsimonious trees based on the 17 most significant characters. Two (or more) plausible interpretations of the data is what makes constructive scientific

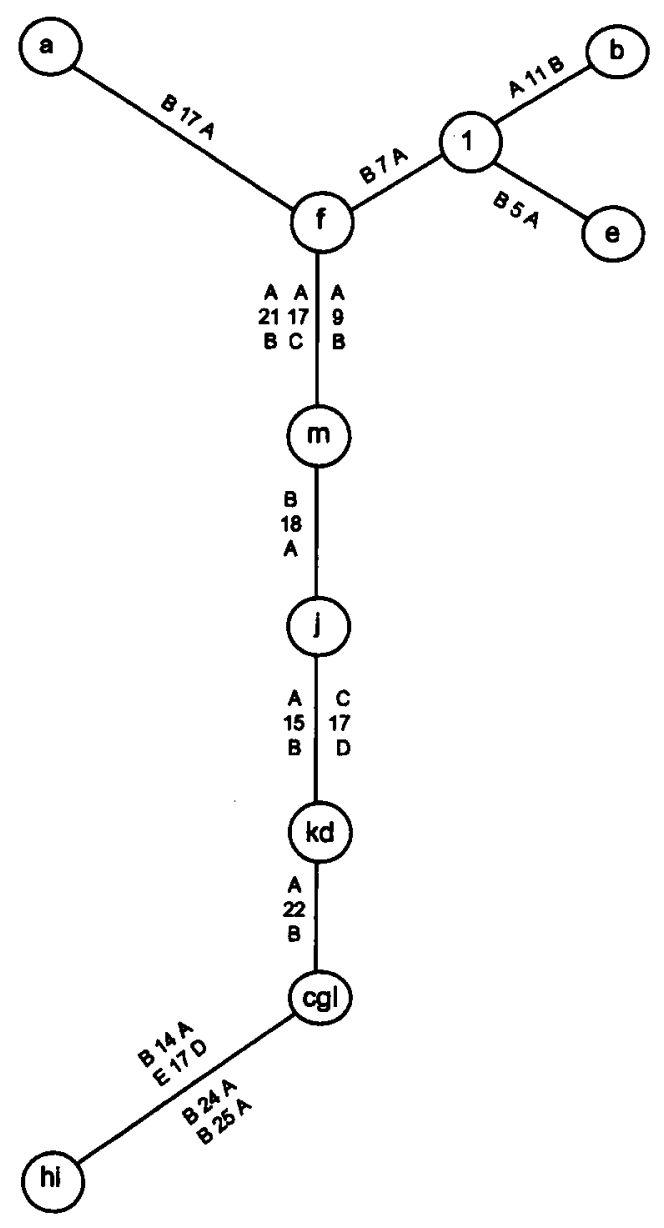

Figure 8. Undirected branching pattern for characters 5, 7, 9, 11, 14, 15, 17, 18, 21, 22, 24 and 25 of Table 2 and 13 species of Iberobathynella as before. 
debate. Our methods indicate that three interpretations have some merit, and show explicitly where the incompatibilities lie.

There have been only a few phylogenetic inference studies for taxa with subterranean environments. Schminke (1973) discussed relationships among the species of several genera of Bathynellacea. His study of Iberobathynella was based on the five species known at that time. It is interesting to note that his estimate of the relationships among those five species is consistent with Figure 7. Iberobathynella now comprises 13 species, eight more than the five he studied.

Notenboom (1988) and Boutin \& Coineau (1988) have performed parsimony analyses of the species of Pseudoniphargus (Amphipoda). Bellés (1985) performed a cladistic analysis of the genera of the subfamily Gibbiinae (Coleoptera), and of the species of Gibbium and Mezium of the family Ptinidae (Coleopotera), many of which live in caves. Cladistic analyses have been performed also by Peck (1984) on Ptomaphagus (Coleoptera), and by Boutin, Mesoull \& Coineau (1992) on a group of species of Metacrangonyx amphipods in North Africa and Desutter-Grandcolas (1993) on cave crickets. More recently, Boutin (1994) includes phylogeny in his treatment of Metacrangonycitidae. These studies hypothesize direction of evolutionary change, and attempt to treat all characters as somehow equal, without explicitly evaluating them.

More sampling and more patient comparison of homologous features among all

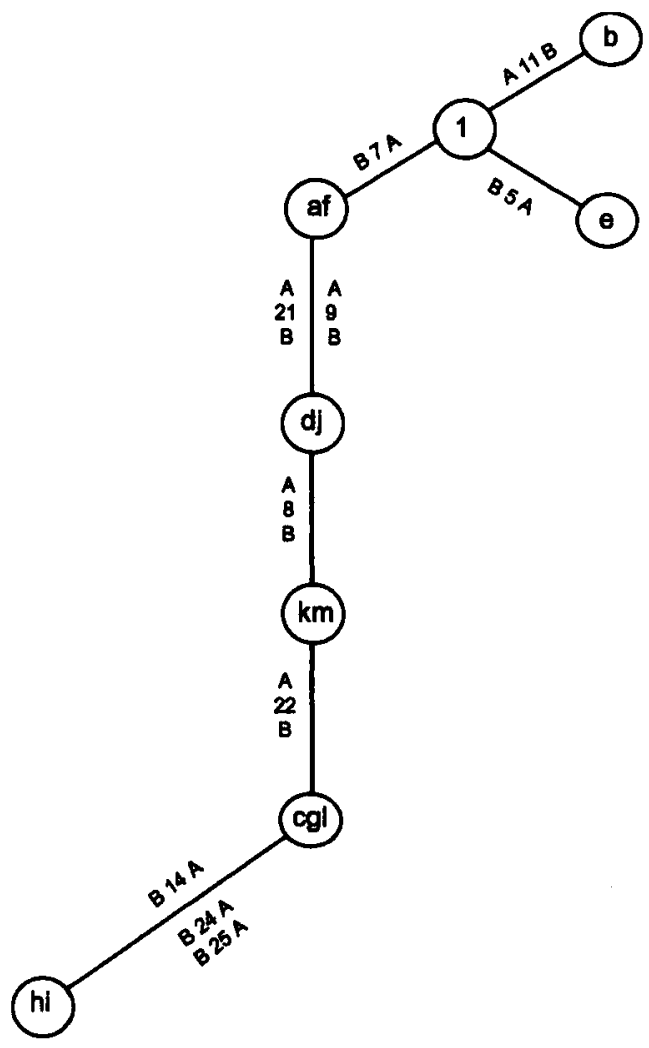

Figure 9. Undirected branches, pattern for characters 5, 7, 8, 9, 11, 14, 21, 22, 24 and 25 of Table 2 and 13 species of lberobathynella as before. 
species are needed to improve the accuracy and completeness of data on which to base inferences of evolutionary relationships. However, clear conceptualizations of how past evolutionary events can result in the similarities and differences we observe today among species are also necessary to give us accurate and straightforward methods for evaluating characters to see how well they indicate those evolutionary events. The concepts and methods that we have described and used in this study of the evolutionary relationships among the 13 known species of Iberobathynella will
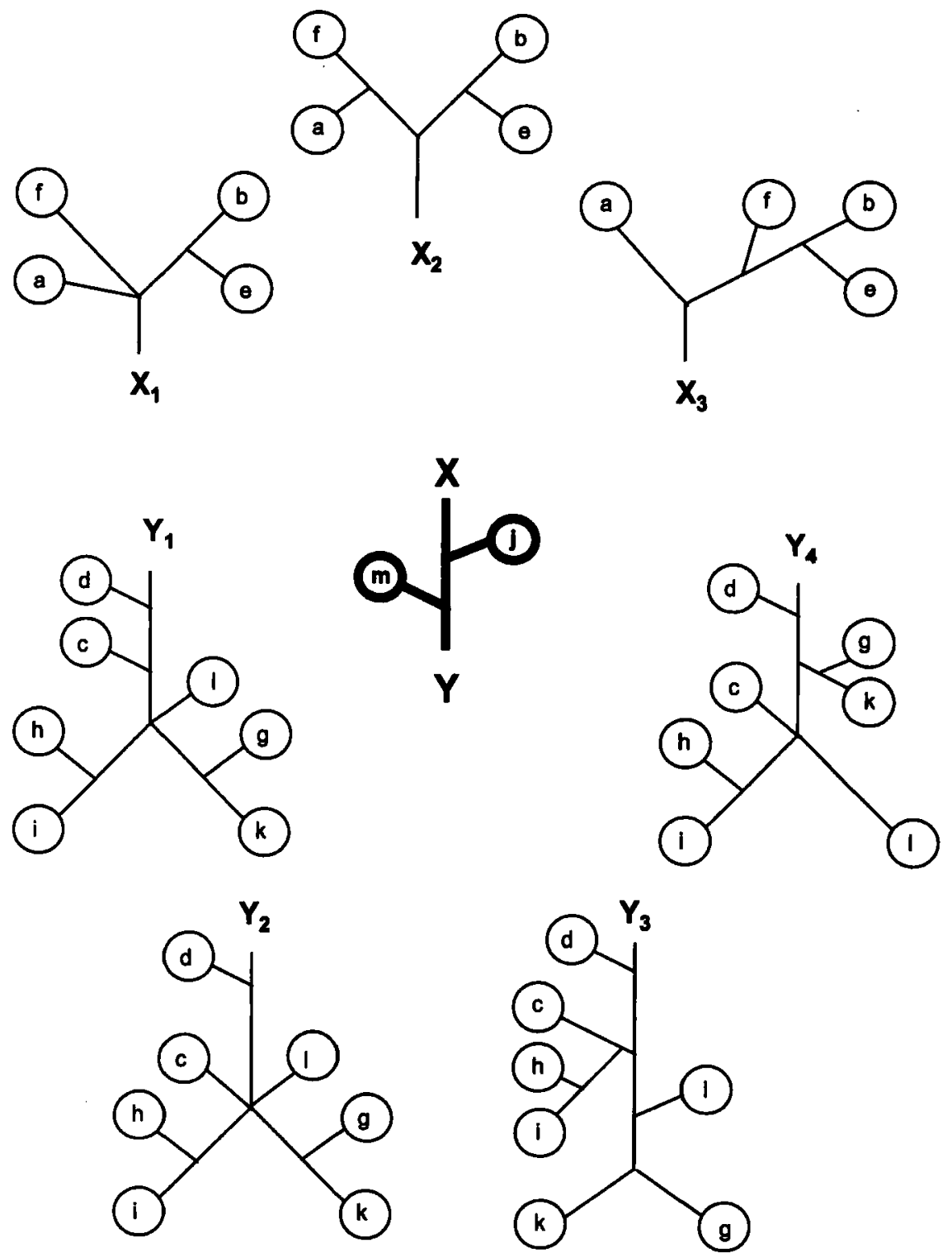

Figure 10. The 12 most parsimonious trees for characters 5-9, 11-15 and 17-25 of Table 2 and the 13 species of Iberobathynella as before, shown as the product of three resolutions of node (f) Figure 7 , represented by $X$, and 4 resolutions of node (c,d) Figure 7, represented by $Y$. When any of $X 1, X 2$ or $\mathrm{X} 3$ is substituted for $\mathrm{X}$, and any of $\mathrm{Y} 1, \mathrm{Y} 2$, $\mathrm{Y} 3$ or $\mathrm{Y} 4$ is substituted for $\mathrm{Y}$, one of the 12 most parsimonious trees results. 
enable others to clearly see what data we have used, follow our reasoning, and evaluate the evolutionary relationships we have consequently proposed. Such approaches will enable us to resolve conflict more accurately and to clarify our understanding of the products and processes of evolution.

\section{AGKNOWLEDGEMENTS}

We gratefully acknowledge the unselfish help and collaboration of Antonio G.-Valdecasas during all the stages of this study. Nicole Coineau provided the original drawings of the type of I. fagei and I. maghrebensis. Carlos Puch and Jose Becerra have helped in many ways, especially with their encouragement. We thank H.K. Schminke and another anonymous reviewer for their close reading of an earlier draft of the descriptions, characters (Table 2), and Figures 1-5 which resulted in improved accuracy, clarity and consistency. These reviewers do not necessarily endorse our data analysis methods or conclusions. This work was supported in part by projects PB89-0081 and PB89-0044 of DGIGYT and by CAM grant to Elisa Bello, and by the University of Michigan Herbarium (G.F. Estabrook) for the development of computer methods for the study of comparative biology. We invite readers who would like to try the computer methods we used to contact George Estabrook.

\section{REFERENCES}

Barr TC. 1968. Cave ecology and evolution of troglobites. In: Dobzhansky Th, Hecht MK, Steere WmC, eds. Evolutionary Biology 2. Amsterdam: North Holland Publishing Co, 35-102.

Bellés X. 1985. Sistemática, filogenia y biogeografia de la subfamilia Gibbiinae (Coleoptera, Ptinidae). Treballs del Museu de Zoologia 3: 1-94.

Birstein JA, Ljovuschkin SI. 1967. Biospeologica Sovietica XXXIII. The order Bathynellaceae (Crustacea Malacostraca) in the U.S.S.R.I. Family Bathynellidae. Biuleten Moskouskogo Obschestua Ispytatelei prirody otgel Biologuii, T. LXXII 4: 51-66.

Boutin C. 1994. Phylogeny and biogeography of metacrangonyctid amphipods in North Africa. Hydrobilogia 287: $49-64$.

Boutin C, Coineau N. 1987. Présence du genre lberobathynella sur le continent africain. Implications paléogéographiques. Comptes rendues de l'Académie des Sciences, Paris 304, Sér. III, 13: 355-358.

Boutin C, Coineau N. 1988. Pseudomiphargus maroctanus n. sp. (subterranean amphipod). The first representative of the genus in Morocco. Phylogenetic relationships and paleobiogeography. Crustaceana suppl, 13: 1-19.

Boutin C, Mesoull M, Coineau N. 1992. Phylogéographie évolutive d'un groupe de Metacrangonyctidae, Crustacés Amphipodes du Maroc. II - cladistique et paléobiogéographic. Avec l'examen comparatif de plusieurs Logiciels de parcimonie. Stygologia 7: 159-178.

Braga JM. 1949. Un Bathynellidae (Crust. Syncarida) du Portugal (Parabathynella lusitanica n.sp.). Publicaçōes do Instituto de Zoologia 'Dr. Augusto Nobre' 40: 1-15.

Braga JM. 1960. Sur une Parabathynella (Crust. Syncarida) nouvelle du Portugal. Publicafões do Instituto de Zoologie 'Dr. Augusto Nobre' 75: 9-22.

Camacho AI. 1987a. A new subterranean syncarid (Crustacea) from Spain: Iberobathynella imuniensis n.sp. (Bathynellacea, Parabathynellidae). Archiv. fuir Hydrobiologie 111(1): 137-149.

Gamacho AI. 1987b. La familia Parabathynellidae (Crustacea, Syncarida, Bathynellacea) en la Península Ibérica. Taxonomia, Filogenia y Biogeografia. Tesis Doctoral, Universidad Autonoma de Madrid, 1-889.

Gamacho AI. 1989a. A new species of the 'mateusi' group: Iberobathynella ortizi sp. n. (Crustacea, Syncarida, Parabathynellidae). Zoologica Scripta 18(3): 405-410.

Gamacho AI. 1989b. Iberobathynella notemboomi, spec. nov. from a well in Alicante, South-East Spain. Spixiana 12(2): 105-113.

Camacho AI, Coineau N. 1987. Un nouveau représentant du genre Iberobathynella Schminke en Espagne: I. rouchi n.sp. (Syncarida, Bathynellacea). Remarques phylogénétiques et paléobiogéographiques. Stygologia $3(2)$ : 125-137.

Chappuis PA. 1915. Bathynella natans und ihre Stellung im System. Zoologische Jahrbücher (Syst) 40(1/2): 147-176. 
Chappuis PA. 1926. Parabathynella stygia n.g., n.sp., nouveau Crustacé cavernicole de la Serbie Orientale. Buletinul Societatii de Stinte din Cluj 3(1): 7-10.

Culver DC. 1982. Cave Life: Evolution and Ecology. Cambridge: Harvard University Press, 189.

Delamare Deboutteville G, Angelier E. 1950. Sur un type de crustacé phréaticole nouveau: Parabathynella fagei n.sp. Comptes rendus du l'Académie des Sciences, Panis 231: 175-176.

Delamare Deboutteville G, Coineau N, Serban E. 1975. Découverte de la famille des Parabathynellidae (Bathynellacea) en Amerique du Nord: Texanobathynella bozmani n.g., n.sp. Cr. Acad. Sc. Paris, 280. Serie D: 2223-2226.

Desutter-Grandcolas, C. 1993. The cricket fauna of Chiapanecan caves (Mexico): Systematics, phylogeny, and the evolution of Troglobitic Life (Orthoptera, Grylloidea, Phalangopsidae, Luzarinae). International Joumal of Speleology 22: 1-82.

Estabrook GF. 1983. The causes of character incompatibility. In: Felsenstein J, ed. Numerical Taxonomy. NATO GSI, Series G] 279-95. Berlin, Germany.

Estabrook GF. 1993. POTENT User's Document. Ann Arbor, MI: University of Michigan Herbarium.

Estabrook GF, Landrum LR. 1975. A simple test for the possible simultaneous evolutionary divergence of two amino acid positions. Taxon 24: 609-613.

Estabrook GF, McMorris FR. 1977. When are two qualitative taxonomic characters compatible? foumal of Mathematical Biology 4: 195-200.

Galhano MH. 1967. Sur une nouvelle Parabathynella psammique du Portugal. Publicaf̧ões do Instituto de Zoologia 'Dr. Augusto Nobre' 98: 1-18.

Galhano MH. 1970. Contribuição para o conhecimento de fauna intersticial em Portugal. Parabathynella lusitanica valbonensis ssp. n. Rublicações do Instituto de Zoologia 'Dr. Augusto Nobre', 110: 77-82 e 148-153.

Meacham CA. 1981. A probability measure for character compatibility. Mathematical BioScience 57: 1-18.

Meacham CA. 1994. Phylogenetic relationships at the basal radiation of Angiosperms: further study by probability of compatibility. Systematic Botany 19: 506-522.

Meacham CA, Estabrook GF. 1985. Compatibility methods in systematics. Annual Review of Ecology and Systematics 16: 431 .

Noodt W. 1965. Natürliches System und Biogeographie der Syncarida (Crustacea, Malacostraca). Gewässer und Abwässer 37/38: 77-186.

Noodt W, Galhano MH. 1969. Studien der Crustacea subterranea (Isopoda, Syncarida, Copepoda) aus dem Norden Portugal. Publicafões do Instituto de Zoologia 'Dr. Augusto Nobre' 107: 9-75.

Notenboom J. 1988. Phylogenetic relationships and biogeography of the groundwater-dwelling amphipod genus Pseudoniphargus (Crustacea), with emphasis on the Iberian species. Bijdragen tot de Dierkunde 58(2): 159-204.

Packard AS. 1885. The Syncarida: a group of carboniferous Crustacea. American Naturalist 19: 700-103.

Peck SB. 1984. The distribution and evolution of cavernicolous Ptomophagus beetles in the southeastern United States (Coleoptera, Leiodidae, Cholevinae) with new species and records. Canadian Joumal of Zoology 62: $730-740$.

Poulson TL, White WB. 1969. The cave environment: limestone caves provide unique natural laboratories in which biological and geological processes are being studied. Science 165: 971-981.

Romero A. 1985. Can evolution regress? National Speleological Society Bulletin 47(2): 86-88.

Rouch R. 1986. Sur l'écologie des eaux souterraines dans le karst. Stygologia 2(4): 352-399.

Schminke HK. 1973. Evolution, System und Verbreitungs-geschichte der Familie Parabathynellidae (Bathynellacea, Malacostraca). Akademie der Wissenschaften und der Literatur Mainz, Mathematisch-Natunwissenschafliche Klasse, Mikrofauna des Meeresboden 24: 1-192.

Schminke HK. 1986. Syncarida. In: Botosaneau L. ed. Stygofauna Mundi. Leiden: Brill, 390-404.

Schminke HK, Noodt W. 1988. Groundwater crustacea of the order Bathynellacea (Malacostraca) from North America. Joumal of Crustacean Biology 8(2): 290-299.

Serban E, Comas i Navarro J. 1978. Contribution à la connaissance du genre lberobathynella Schminke: $I$. asturiensis n.sp. et $I$. espaniensis n.sp. nouvelles espèces d'Espagne (Bathynellacea, Parabathynellidae). Travaux de l'Institut de Spéologie, Emile Racovitza 17: 13-37.

Swafford DL. 1993. Phylogenetic Inference Using Parsimony (version 3.1.1) Champagne, IL: Illinois Natural History.

Vejdovsky F. 1882. Tierische Organismen der Brunnenwasser vom Prag. Prague.

Wilkens H. 1971. Genetic interpretation of regressive evolutionary processes: Studies on hybrid eyes of two Astyanax cave populations. Evolution 25(3): 530-544. 